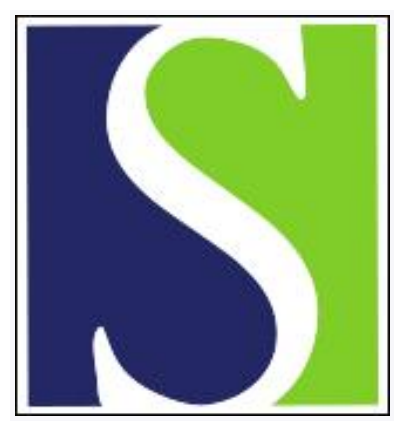

Scand J Work Environ Health 2008;34(6):444-450

https://doi.org/10.5271/sjweh.1296

Issue date: 00 Dec 2008

\title{
Exposure to iron and welding fumes and the risk of lung
} cancer

by Siew SS, Kauppinen T, Kyyrönen P, Heikkilä P, Pukkala E

Affiliation: Finnish Institute of Occupational Health, Topeliuksenkatu 41 a A, Fl-00250 Helsinki, Finland. angelica.siew@ttl.fi

Refers to the following texts of the Journal: 2007;33(5):379-386

2006;32(1):22-31 1997;23(2):104-113 2005;31(2):97-107

The following article refers to this text: $2022 ; 48(1): 21-30$

Key terms: exposure; iron; job-exposure matrix; lung cancer; occupational epidemiology; register-based study; risk; welding fume

This article in PubMed: www.ncbi.nlm.nih.gov/pubmed/19137206 


\title{
Exposure to iron and welding fumes and the risk of lung cancer
}

\author{
by Sie Sie Siew, MSc, ${ }^{1}$ Timo Kauppinen, PhD, ${ }^{1}$ Pentti Kyyrönen, ${ }^{2}$ Pirjo Heikkilä, PhD, ${ }^{1}$ \\ Eero Pukkala, PhD ${ }^{2,3}$
}

\begin{abstract}
Siew SS, Kauppinen T, Kyyrönen P, Heikkilä P, Pukkala E. Exposure to iron and welding fumes and the risk of lung cancer. Scand J Work Environ Health 2008:34(6):444-450.
\end{abstract}

\begin{abstract}
Objectives Exposure to iron fumes and dust and welding fumes is widespread and may increase the risk of lung cancer. The aim of this study was to identify associations between exposure to iron and welding fumes and the incidence of lung cancer among Finnish men.

Methods The cohort of all economically active Finnish men, born in 1906-1945, who participated in the national census in 1970 was followed through the Finnish Cancer Registry for lung cancer cases (N=30 137) during 1971-1995. Their census occupations in 1970 were converted to estimates of cumulative exposure to iron and welding fumes with the Finnish job-exposure matrix on the basis of likelihood, average level, and estimated duration of exposure. Relative risk estimates for categorized cumulative exposure were defined by a Poisson regression, adjusted for smoking, socioeconomic status, and exposure to asbestos and silica dust.

Results The relative risks for lung cancer increased as the cumulative exposure to iron and welding fumes increased. The relative risks in the highest exposure category was 1.35 [95\% confidence interval $(95 \% \mathrm{CI})$ 1.05-1.73] for iron and 1.15 (95\% CI 0.90-1.46) for welding fumes. The respective relative risks estimated for squamous-cell carcinoma of the lungs were 1.94 (95\% CI 1.35-2.78) and 1.55 (95\% CI 1.08-2.24). There was no excess risk of small-cell carcinoma in any exposure category.

Conclusions Occupational exposure to iron and welding fumes was associated with an increase in lung cancer risk, mainly that of squamous-cell carcinoma. The simultaneous exposure to both of these agents and other potential work-related carcinogens complicates the interpretation of the independent roles of the risk factors.
\end{abstract}

Key terms job-exposure matrix; register-based study; occupational epidemiology.

There is extensive exposure to iron fumes or dust and welding fumes in the work environment across various industries worldwide. In Finland, the estimated number of workers exposed to iron fumes or dust or welding fumes in 1960-1984 was about 100000 (ie, 4\% of the 2.3 million economically active population) (1). Twothirds of them were exposed to welding fumes, which contain iron fumes as one component. If it is assumed that $1 \%$ of the 2.9 billion global workforce perform welding as part of their work duties, the number of exposed workers would be about 30 million. In Finland, the most common occupations with exposure to welding fumes are welder $(\mathrm{N}=15000)$, machine and engine mechanic $(\mathrm{N}=12000)$, sheet metal worker $(\mathrm{N}=15000)$, and plumber $(\mathrm{N}=12000)$. There are also occupations with no exposure to welding fumes but which have exposure to iron fumes or dust, such as foundry and steel work.
Due to the widespread exposure, the number of cancer cases attributable to exposure to iron fumes or dust or welding fumes would be very high if iron fumes or dust or welding fumes turn out to be carcinogenic.

In 1990, the International Agency for Research on Cancer (IARC) categorized welding fumes as possibly carcinogenic to humans (group 2B) on the basis on 23 epidemiologic studies. The National Institute of Occupational Safety and Health (NIOSH) concluded that there is an elevated risk of lung cancer among welders that cannot be completely accounted for by smoking or asbestos exposure (2). More recent papers also support the view that welding fumes could increase the risk of lung cancer (3-10).

On the other hand, iron dust and fumes were not classified as carcinogenic by the American Conference of Governmental Industrial Hygienists (10), and they have

Finnish Institute of Occupational Health, Helsinki, Finland.

Finnish Cancer Registry, Institute for Statistical and Epidemiological Cancer Research, Helsinki, Finland.

School of Public Health, University of Tampere, Tampere, Finland.

Correspondence to: Siew Sie Sie, Finnish Institute of Occupational Health, Topeliuksenkatu 41 a A, FI-00250 Helsinki, Finland. [E-mail: angelica.siew@ttl.fi] 
not been evaluated by IARC. Although numerous studies suggest that there is an association between exposure to iron fumes or dust at work and lung cancer risk (11-14), the possible effect from other agents in simultaneous exposure could not be ruled out completely. Exposure to iron fumes or dust and welding fumes is associated because the main constituent of welding fumes is iron and its compounds. In most cancer studies in relation to welding fumes, iron is generally neglected because the focus falls upon nickel, chromium or chromium VI, and other possible carcinogens. In addition, there has been a debate about whether exposure to mild steel or stainless steel could lead to an increased risk of lung cancer among welders.

The aim of our present study was to identify the exposure-response relationship of occupational exposure with iron fumes or dust and welding fumes and the risk of lung cancer in a follow-up of the entire Finnish workforce.

\section{Study population and methods}

The study cohort consisted of all of the 1.2 million economically active Finnish men who were born in 1906-1945 and who participated in the national population census on 31 December 1970. The Finnish census data maintained by Statistics Finland were updated for vital status to allow exact person-year calculation. Data on the occupations held for the longest time in 1970 were obtained from the population census 1970 records (15). The occupational classification was based on a modification of the International Standard Classification of Occupations in 1958. Some of the 311 basic occupational codes were further divided according to industry. The cohort was also categorized into the following five socioeconomic strata: higher white-collar, clerical, skilled blue-collar, and unskilled workers, and also farmers. The socioeconomic status of each person was determined on the basis of occupation and education in 1970 (16).

The cancer data were obtained from the Finnish Cancer Registry, which has maintained a nationwide database on all cancer cases in Finland since 1953. It is the responsibility of all physicians, hospitals, institutions, and laboratories to notify the Registry of all diagnosed cancer cases. In addition, Statistics Finland sends the Registry the death certificates on which cancer is mentioned. The data in the Registry are accurate and virtually complete (17). An 11-digit personal identification code has been given to every resident in Finland since 1967, and it is used in health care and all registers throughout the country. The codes allow reliable computerized record linkage. In our present study, the incident cases of lung cancer diagnosed between 1971 and 1995 among men born between 1906 and 1945 (30 137 cases) were extracted from the Finnish Cancer Register and sent to Statistics Finland for linkage with the data in the population census in 1970. Cancer cases of persons who had no record in the 1970 census (2.2\%) were excluded.

The occupational exposure estimates used in this study were based on the Finnish job-exposure matrix (FINJEM) (1). Each occupational category is characterized by the proportion of exposed persons $(\mathrm{P})$ and the mean level of exposure among the exposed (L). The exposure estimates were based on the judgment of about 20 experts at the Finnish Institute of Occupational Health. In our study, iron fumes or dust exposure is defined as the occupational inhalation exposure to iron dust or fumes from welding, smelting, grinding, or other processing of steel and other materials containing iron. It includes metallic iron and all iron compounds. Welding fume exposure is defined as occupational inhalation exposure to fumes from welding. The level of exposure to iron fumes or dust and welding fumes is expressed in milligrams of agent in cubic meters of workroom air. Occupations that had more than 5\% of the persons exposed to the individual agent at any time between 1945 and 1984 are considered as potentially exposed occupations in the FINJEM. For welding fumes, the Pvalues were collected mainly from the work and health surveys carried out by the Finnish Institute of Occupational Health in 1997-2003, whereas the mean levels of exposure were estimated on the basis of exposure measurements made by the the same institute. The FINJEM also includes exposure estimates for asbestos, silica, nickel, chromium, lead, benzo(a)pyrene, and smoking, which are potential confounders in our current study. Smoking is expressed as the proportion of those in the occupation who smoked daily, according to data from annual surveys on the health behavior of the Finnish adult population in 1978-1991 (18).

We estimated the agent-specific and occupation-specific cumulative exposure (cumulative exposure) for every 5-year birth cohort (from 1906-1910 to 1941-1945) and 5-year calendar periods of observation from 19711975 to 1991-1995 (figure 1). For each birth cohort, it was assumed that the exposure started when the average age of the birth cohort was 20 years and ended in the middle year of the observation period minus 20 years (latency) or at 65 years of age, whichever came first. In each calendar year, the annual average exposure was the product of the proportion of exposed persons and the mean level of exposure in that occupation. When the exposure occurred before 1960, we used the FINJEM estimates for the period 1945-1959; otherwise the estimates for the period 1960-1984 were used.

The limits of the cumulative exposure categories for all of the chemical agents were set a priori on the basis 


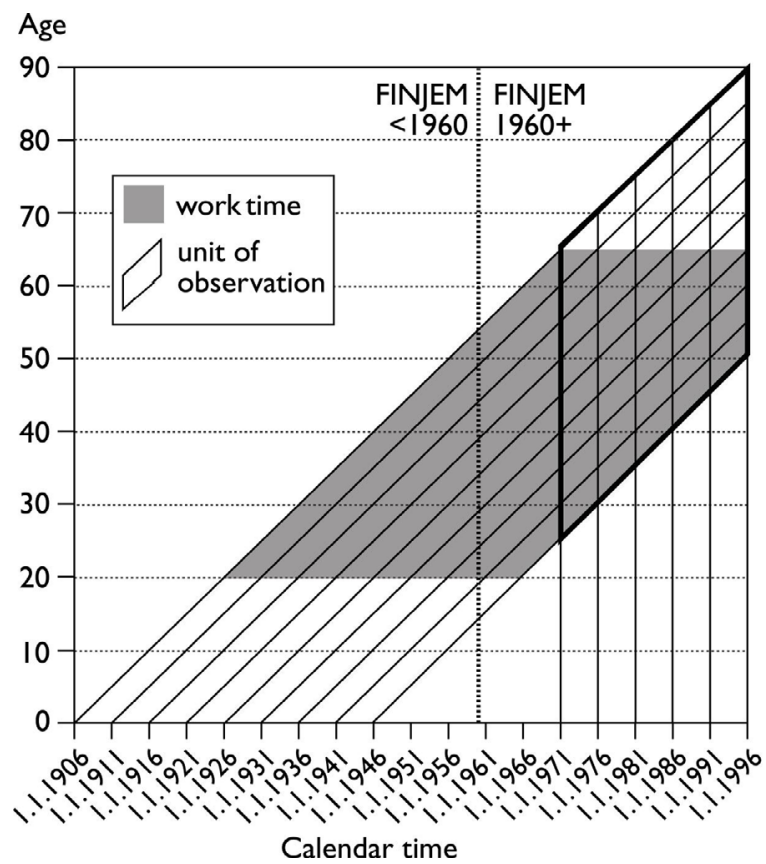

Figure 1. Units of observation, defined by birth year of the persons in the cohort (1906-1910 through 1941-1945) and calendar period of follow-up (1971-1975 through 1991-1995), theoretical exposure (work) time, and the periods of the Finnish job-exposure matrix (FINJEM) used for estimating the exposure.

of the distribution of the exposures in such a way that the highest category included only the cluster of workers with evidently the highest exposure (ie, not automatically to include, for example, one-fourth of the population). The rest of the potentially exposed workers were divided into medium and low categories. The categorized cumulative exposures to iron fumes or dust were $0.1-9.9 \mathrm{mg} / \mathrm{m}^{3}$-years (low), $10-49.9 \mathrm{mg} / \mathrm{m}^{3}$-years (medium), and $\geq 50 \mathrm{mg} / \mathrm{m}^{3}$-years. The respective thresholds for welding fumes were 100 and $200 \mathrm{mg} / \mathrm{m}^{3}$-years.

The expected numbers of cases for every occupation were calculated for each 5-year birth cohort and 5-year calendar period (figure 1) by multiplying person-years lived by persons in that occupation with the cancer incidence rate of the entire Finnish population in the respective stratum. The standardized incidence ratio was defined as the ratio of the observed number of cases to the expected number of cases.

The exposure-response patterns were studied with the Poisson regression analysis of the stratum-specific observed numbers of cases and person-years at risk. The unexposed persons formed the reference category.

Statistical analyses were conducted separately for exposure to iron fumes or dust and welding fumes because they were strongly correlated with each other. Smoking and occupational exposure to asbestos and silica could be controlled in the Poisson regression models because their mutual correlations and the correlations with iron fumes or dust and welding fumes were rather weak. Occupational exposure to nickel, chromium, lead, and benzo(a)pyrene were so strongly correlated with iron fumes or dust and welding fumes that they could not be included in the statistical model. The Pearson correlations of the cumulative exposure between iron fumes or dust and nickel, chromium, lead, and benzo(a)pyrene were $0.79,0.66,0.62$, and 0.63 , respectively, and those for welding fumes were $0.80,0.68$, 0.64 , and 0.53 , respectively. Their potential confounding effect was limited by excluding the workers who had high or moderate cumulative exposure to these agents from the cohort.

\section{Results}

Table 1 shows the occupations exposed to iron fumes or dust and welding fumes and the standardized incidence ratios (SIR) of lung cancer in these occupations. The exposure decreased slightly from 1945-1959 to 1960-1984. The highest standardized incidence ratio [SIR 1.81, 95\% confidence interval $(95 \% \mathrm{CI})$ 1.42-2.27] was found for sheet metal workers in the building industry.

The relative risk for lung cancer increased as the cumulative exposure increased for iron fumes or dust and welding fumes (tables 2-3). The relative risk in the highest exposure category was 1.35 (95\% CI 1.05-1.73) for iron fumes or dust (table 2) and 1.15 (95\% CI 0.90-1.46) (table 3) for welding fumes. The parameter correlation for exposure to iron fumes or dust and welding fumes is so high (correlation 0.86) that it was not possible to put both factors in the same model.

The exclusion of the high-exposure categories of nickel, chromium, lead, and benzo(a)pyrene did not change the relative risk estimate for the highest cumulative exposure to iron fumes or dust but increased the relative risk for medium exposure (table 2). Further exclusion of the high-exposure categories of welding fumes increased the relative risk (RR) for the highest cumulative iron fumes or dust exposure (RR 1.57, 1.17-2.09).

The exclusion of the high-exposure categories for nickel, chromium, lead, benzo(a)pyrene, and iron fumes or dust did not markedly change the relative risk estimate for welding fume exposure (table 3 ).

Of the histological subtypes of lung cancer, squamous-cell carcinoma showed the strongest dose-response relationship (tables 4 and 5). The relative risk of the highest category of iron fumes or dust was 1.94 (95\% CI 1.35-2.78) and that of the highest category of welding fumes was 1.55 (95\% CI 1.08-2.24). The pattern for adenocarcinoma was less consistent, and there was virtually no excess risk in any exposure category for small-cell carcinoma. 
Table 1. Exposure to iron fumes or dust and welding fumes, according to the Finnish job-exposure matrix, and the incidence of lung cancer by occupation among the Finnish men who were born in 1906-1946 and who participated in the population census in 1970. [P = proportion of exposed persons, $\mathrm{L}=$ level (mean) of exposure, $\mathrm{SIR}=$ standardized incidence ratio, $95 \% \mathrm{Cl}=95 \%$ confidence interval, $\mathrm{NEC}=$ not elsewhere classified]

\begin{tabular}{|c|c|c|c|c|c|c|c|c|c|c|c|c|}
\hline \multirow[t]{3}{*}{ Occupation a } & \multicolumn{4}{|c|}{ Iron fumes or dust } & \multicolumn{4}{|c|}{ Welding fumes } & \multirow{3}{*}{$\begin{array}{c}\text { Daily } \\
\text { smoking } \\
\text { (1978- } \\
1991) \\
P \\
(\%)\end{array}$} & \multirow{2}{*}{\multicolumn{3}{|c|}{$\begin{array}{c}\text { Risk of } \\
\text { lung cancer } \\
\text { (1971-1995) }\end{array}$}} \\
\hline & \multicolumn{2}{|c|}{$1945-1959$} & \multicolumn{2}{|c|}{$1960-1984$} & \multicolumn{2}{|c|}{$1945-1959$} & \multicolumn{2}{|c|}{$1960-1984$} & & & & \\
\hline & $\begin{array}{c}P \\
(\%)\end{array}$ & $\stackrel{\mathrm{L}}{\left.\mathrm{mg} / \mathrm{m}^{3}\right)}$ & $\underset{(\%)}{P}$ & $\stackrel{\mathrm{L}}{\left.\mathrm{mg} / \mathrm{m}^{3}\right)}$ & $\begin{array}{c}P \\
(\%)\end{array}$ & $\stackrel{\mathrm{L}}{\left.\mathrm{mg} / \mathrm{m}^{3}\right)}$ & $\begin{array}{c}P \\
(\%)(\end{array}$ & $\stackrel{\mathrm{L}}{\left.\mathrm{mg} / \mathrm{m}^{3}\right)}$ & & $\begin{array}{l}\text { Observed } \\
\text { cases } \\
\text { (N) }\end{array}$ & $d S^{b}$ & $95 \% \mathrm{Cl}$ \\
\hline Smelter worker, iron or steel (6301) & 100 & 1.5 & 100 & 0.9 & 10 & 0.9 & 10 & 0.9 & 54 & 28 & 1.04 & $0.69-1.50$ \\
\hline Smelter worker, NEC (6309) & 85 & 0.80 & 85 & 0.50 & 10 & 0.9 & 10 & 0.9 & 54 & 14 & 0.85 & $0.46-1.43$ \\
\hline Hardener, temperer, etc (6310) & 90 & 0.50 & 90 & 0.25 & 10 & 0.9 & 10 & 0.9 & 47 & 10 & 1.33 & $0.64-2.45$ \\
\hline Hot-roller (6320) & 90 & 0.50 & 90 & 0.25 & 10 & 0.9 & 10 & 0.9 & 47 & 19 & 1.40 & $0.85-2.19$ \\
\hline Cold-roller (6330) & 90 & 0.20 & 90 & 0.10 & 10 & 0.9 & 10 & 0.9 & 47 & 5 & 0.91 & $0.30-2.13$ \\
\hline Blacksmith (6340) & 90 & 0.50 & 90 & 0.25 & 15 & 0.9 & 15 & 0.9 & 47 & 117 & 1.43 & $1.18-1.71$ \\
\hline Foundry worker, iron or steel (6351) & 90 & 2.00 & 90 & 1.70 & 5 & 0.9 & 5 & 0.9 & 46 & 43 & 1.27 & $0.92-1.70$ \\
\hline Foundry worker, NEC (6359) & 90 & 1.00 & 90 & 0.80 & 5 & 0.9 & 5 & 0.9 & 46 & 73 & 0.25 & $0.98-1.57$ \\
\hline Wire and tube drawer (6360) & 60 & 0.50 & 60 & 0.25 & 10 & 0.9 & 10 & 0.9 & 47 & 14 & 1.29 & $0.71-2.17$ \\
\hline Metal mill worker, iron or steel (6391) & 70 & 0.50 & 70 & 0.25 & 5 & 0.5 & 5 & 0.5 & 44 & 24 & 1.33 & $0.85-1.97$ \\
\hline Metal mill worker, NEC (6399) & 70 & 0.20 & 70 & 0.10 & 5 & 0.5 & 5 & 0.5 & 44 & 42 & 1.15 & $0.83-1.56$ \\
\hline Turner, machinist (6500) & 90 & 0.50 & 90 & 0.30 & 5 & 0.9 & 5 & 0.9 & 36 & 522 & 0.98 & $0.89-1.06$ \\
\hline Fitter-assembler, etc (6510) & 50 & 0.20 & 50 & 0.20 & 40 & 0.9 & 40 & 0.9 & 37 & 212 & 0.91 & $0.79-1.04$ \\
\hline Car mechanic (6521) & 50 & 0.20 & 50 & 0.17 & 40 & 0.3 & 40 & 0.3 & 39 & 266 & 1.14 & $1.01-1.29$ \\
\hline Machine repairer, except cars (6529) & 50 & 0.20 & 50 & 0.17 & 40 & 0.3 & 40 & 0.3 & 39 & 305 & 1.00 & $0.89-1.12$ \\
\hline Sheetmetal worker, building (6531) & 90 & 1.50 & 90 & 1.00 & 75 & 4.0 & 90 & 3.5 & 40 & 75 & 1.81 & $1.42-2.27$ \\
\hline Sheetmetal worker, except building (6539) & 90 & 2.70 & 90 & 2.00 & 75 & 8.0 & 90 & 7.0 & 40 & 203 & 1.18 & $1.02-1.35$ \\
\hline Plumber, building (6541) & 50 & 0.05 & 50 & 0.05 & 50 & 0.5 & 50 & 0.5 & 35 & 243 & 1.30 & $1.14-1.47$ \\
\hline Plumber, except building (6549) & 50 & 0.05 & 50 & 0.05 & 50 & 0.5 & 50 & 0.5 & 35 & 134 & 1.17 & $0.98-1.39$ \\
\hline Welder and flame cutter, stainless steel $>10 \%$ (6551) & 100 & 2.00 & 100 & 1.50 & 100 & 6.0 & 100 & 4.5 & 44 & 110 & 0.95 & $0.78-1.15$ \\
\hline Welder, shipyard (6552) & 100 & 3.30 & 100 & 2.60 & 100 & 10.0 & 100 & 8.0 & 44 & 26 & 1.05 & $0.69-1.55$ \\
\hline Welder, building (6553) & 80 & 2.00 & 80 & 1.50 & 80 & 6.0 & 80 & 4.5 & 44 & 24 & 1.31 & $0.84-1.95$ \\
\hline Welder, NEC (6559) & 80 & 3.00 & 70 & 2.10 & 80 & 9.0 & 70 & 6.5 & 44 & 102 & 1.39 & $1.14-1.69$ \\
\hline Plate or constructional steel worker (6560) & 80 & 0.80 & 80 & 0.80 & 60 & 2.0 & 60 & 2.0 & 40 & 69 & 0.97 & $0.75-1.23$ \\
\hline Metal plater and coater (6570) & 50 & 0.03 & 50 & 0.03 & 5 & 0.2 & 5 & 0.2 & 40 & 23 & 1.63 & $1.03-2.45$ \\
\hline Machine shop worker, NEC (6590) & 25 & 0.50 & 25 & 0.50 & 10 & 0.9 & 10 & 0.9 & 40 & 260 & 1.16 & $1.02-1.31$ \\
\hline
\end{tabular}

a The occupational code of the Finnish job-exposure matrix is given in parentheses after the occupation.

${ }^{\mathrm{b}}$ Reference population: all Finnish men.

\section{Discussion}

The excess risk of lung cancer among the Finnish male workers having the highest exposure to welding fumes was $15 \%$, which is in accordance with the excess risk suggested by a meta-analysis of 60 studies related to welding fumes in 1954-2004 (4). The excess related to the highest exposure to iron fumes or dust was $35 \%$. Due to the high correlation of exposure to iron fumes or dust and welding fumes in several occupational categories, the observed excess risk may not have been allocated accurately between these two exposures. Simultaneous exposure to iron fumes or dust, welding fumes and other potential lung carcinogens at the workplace complicated the interpretation of the independent roles of the risk factors.

A restriction of the analysis to categories without major exposure to the potential confounding agents tended to give slightly higher risk estimates and to illustrate the exposure-response characteristics. The risk re- lated to iron fumes or dust exposure was the strongest for squamous-cell carcinoma, weaker for adenocarcinoma, and nonexisting for small-cell carcinoma of the lung.

An excess risk of lung cancer in relation to iron fumes or dust exposure has been suggested only in a few studies $(10,14,19-21)$. Our findings are in line with these studies. Exposure to iron fumes or dust may give rise to siderosis, an accumulation of iron in the lungs (14, $22,23)$, interstitial pulmonary fibrosis, or siderofibrosis (24), which have been suspected to be associated with an increased risk of lung cancer $(25,26)$. IARC has defined welding fumes as possibly carcinogenic to humans (27). The IARC evaluation of carcinogenicity did not differentiate between exposure to stainless steel welding and mild steel welding, although some previous studies explain the carcinogenic effects as being predominantly related to stainless steel welding. A slight excess risk of lung cancer was suggested in most of the studies among welders, including stainless steel, mild steel, and unspecified welding 
Table 2. Observed number of cases and the relative risk (RR) and $95 \%$ confidence interval $(95 \% \mathrm{Cl})$ for lung cancer, with a 20 -year latency period for cumulative exposure to iron fumes or dust among the Finnish men who were born in 1906-1946 and who participated in the population census in 1970. The workers who had simultaneous high or medium exposure to welding fumes, nickel, chromium, lead, or benzo(a)pyrene were excluded.

Exclusion due to concurrent work-related co-exposure Cumulative exposure to iron fumes or dust

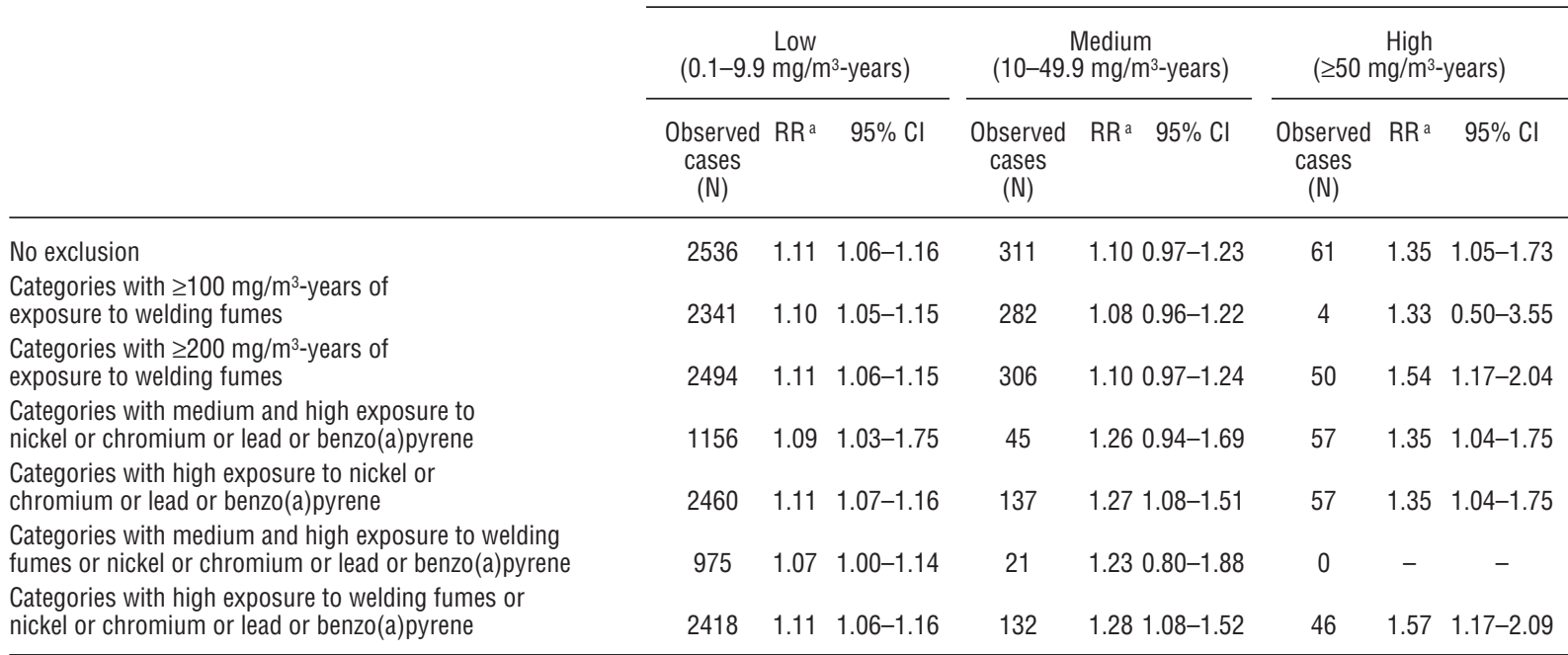

a Adjusted for smoking, exposure to asbestos and silica, socioeconomic status, age, and periods of follow-up, the reference category being workers unexposed to iron.

Table 3. Observed number of cases and the relative risk (RR) and $95 \%$ confidence interval $(95 \% \mathrm{Cl})$ for lung cancer, with a 20 -year latency period for cumulative exposure to welding fumes, among the Finnish men who were born in 1906-1946 and who participated in the population census in 1970 . Workers who had simultaneous high or medium exposure to iron, nickel, chromium, lead, and benzo(a)pyrene were excluded.

Exclusion due to concurrent work-related co-exposure

Cumulative exposure to welding fumes

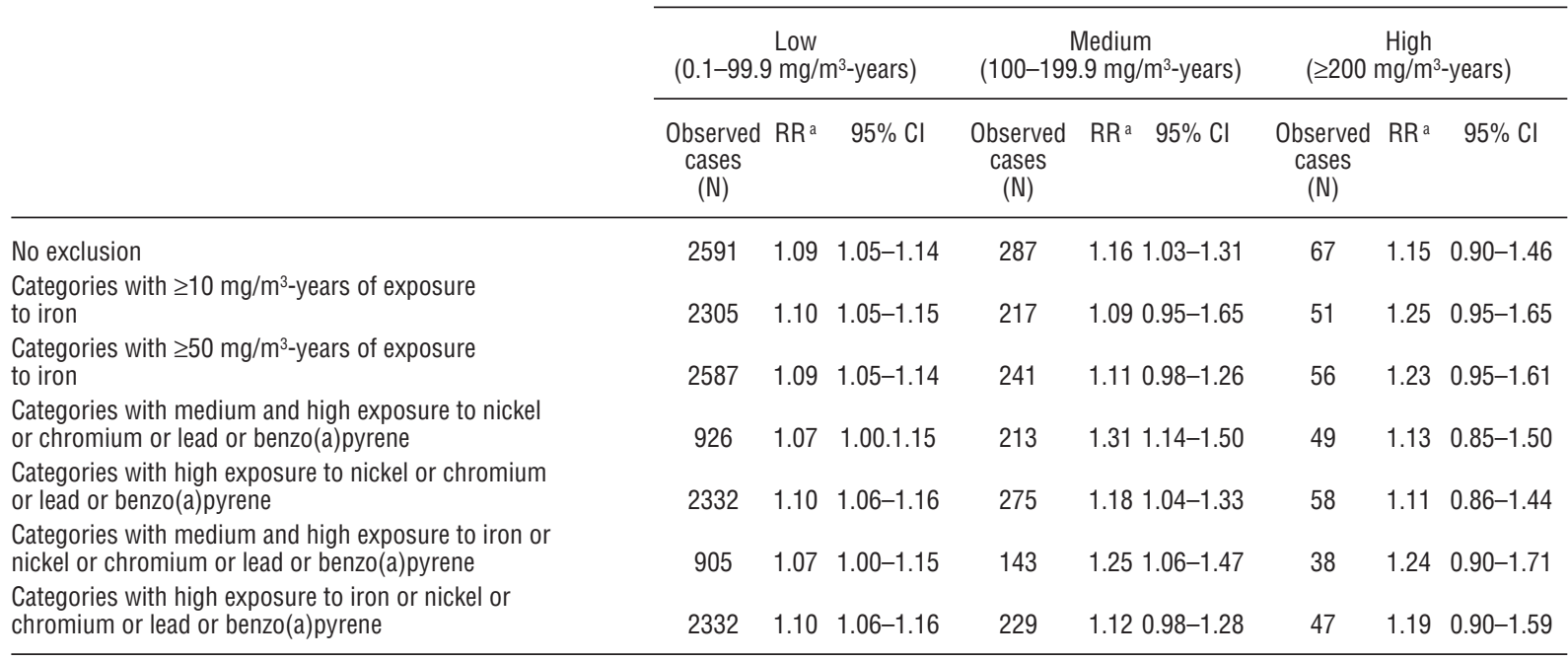

${ }^{a}$ Adjusted for smoking, exposure to asbestos and silica, socioeconomic status, age, and periods of follow-up, the reference category being workers unexposed to welding fumes.

$(4,5,28)$. In our study, we found a higher standardized incidence ratio for mild steel welders in comparison with stainless steel welders (table 1).

The mechanism of carcinogenicity for welding fumes is unresolved. Exposure to any kind of granular biodurable particles may lead to lung cancer, as reported in a series of animal studies (29). Iron particles have also been suggested to contribute to the generation of reactive oxygen or nitrogen species, which may lead to cancer (30).

The general problems in previous studies include too short a follow-up and inadequate control of occupational co-exposures and other confounders. For instance, shipyard welders and car mechanics could have had exposure to asbestos, smelters and foundry workers to silica and 
Table 4. Observed number of cases and the relative risk (RR) and $95 \%$ confidence interval $(95 \% \mathrm{Cl})$ for lung cancer according to its three main types and all types with a 20-year latency period, for cumulative exposure to iron fumes or dust among the Finnish men who were born in 1906-1946 and who participated in the population census in 1970.

\begin{tabular}{|c|c|c|c|c|c|c|c|c|c|c|c|c|}
\hline \multirow[t]{3}{*}{ Cancer type } & \multicolumn{12}{|c|}{ Cumulative exposure to iron fumes or dust } \\
\hline & \multicolumn{3}{|c|}{ None } & \multicolumn{3}{|c|}{$\begin{array}{c}\text { Low } \\
\left(0.1-10 \mathrm{mg} / \mathrm{m}^{3} \text {-years }\right)\end{array}$} & \multicolumn{3}{|c|}{$\begin{array}{c}\text { Medium } \\
\left(10.1-49.9 \mathrm{mg} / \mathrm{m}^{3} \text {-years }\right)\end{array}$} & \multicolumn{3}{|c|}{$\begin{array}{c}\text { High } \\
\left(\geq 50 \mathrm{mg} / \mathrm{m}^{3} \text {-years }\right)\end{array}$} \\
\hline & $\begin{array}{l}\text { Observed } \\
\text { cases }(N)\end{array}$ & $\mathrm{RR}^{\mathrm{a}}$ & $95 \% \mathrm{Cl}$ & $\begin{array}{l}\text { Observe } \\
\text { cases ( }\end{array}$ & $\mathrm{d}^{\mathrm{n}} \mathrm{R}^{\mathrm{a}}$ & $95 \% \mathrm{Cl}$ & $\begin{array}{l}\text { Observed } \\
\text { cases (N) }\end{array}$ & $R^{a}$ & $95 \% \mathrm{Cl}$ & $\begin{array}{l}\text { Observed } \\
\text { cases (N) }\end{array}$ & $R^{a}$ & $95 \% \mathrm{Cl}$ \\
\hline All lung cancers & 27229 & 1.00 & .. & 2536 & 1.11 & $1.06-1.16$ & 311 & 1.10 & $0.97-1.23$ & 61 & 1.35 & $1.05-1.73$ \\
\hline Squamous-cell carcinoma & 9292 & 1.00 & .. & 853 & 1.08 & $1.00-1.16$ & 109 & 1.16 & $0.95-1.41$ & 30 & 1.94 & $1.35-2.78$ \\
\hline Small-cell carcinoma & 4652 & 1.00 & .. & 475 & 1.21 & $1.09-1.33$ & 58 & 1.16 & $0.88-1.52$ & 7 & 0.98 & $0.47-2.01$ \\
\hline Adenocarcinoma & 3392 & 1.00 & .. & 336 & 1.07 & $0.95-1.21$ & 38 & 1.15 & $0.83-1.61$ & 8 & 1.49 & $0.74-2.98$ \\
\hline
\end{tabular}

a Adjusted for smoking, exposure to asbestos and silica, socioeconomic status, age, and periods of follow-up, the reference category being unexposed workers.

Table 5. Observed number of cases and the relative risk (RR) and $95 \%$ confidence interval $(95 \% \mathrm{Cl})$ for lung cancer according to its three main types and all types with a 20-year latency period, for cumulative exposure to welding fumes among the Finnish men who were born in 1906-1946 and who participated in the population census in 1970.

\begin{tabular}{|c|c|c|c|c|c|c|c|c|c|c|c|c|}
\hline \multirow[t]{3}{*}{ Cancer type } & \multicolumn{12}{|c|}{ Cumulative exposure to welding fumes } \\
\hline & \multicolumn{3}{|c|}{ None } & \multicolumn{3}{|c|}{$\begin{array}{c}\text { Low } \\
\left(0.1-10 \mathrm{mg} / \mathrm{m}^{3} \text {-years }\right)\end{array}$} & \multicolumn{3}{|c|}{$\begin{array}{c}\text { Medium } \\
\left(10.1-49.9 \mathrm{mg} / \mathrm{m}^{3} \text {-years }\right)\end{array}$} & \multicolumn{3}{|c|}{$\begin{array}{c}\text { High } \\
\left(\geq 50 \mathrm{mg} / \mathrm{m}^{3} \text {-years }\right)\end{array}$} \\
\hline & $\begin{array}{l}\text { Observed } \\
\text { cases (N) }\end{array}$ & $\mathrm{RR}^{\mathrm{a}}$ & $95 \% \mathrm{Cl}$ & $\begin{array}{l}\text { Observed } \\
\text { cases }(\mathrm{N})\end{array}$ & $\mathrm{RR}^{\mathrm{a}}$ & $95 \% \mathrm{Cl}$ & $\begin{array}{l}\text { Observed } \\
\text { cases (N) }\end{array}$ & $R R^{a}$ & $95 \% \mathrm{Cl}$ & $\begin{array}{l}\text { Observed } \\
\text { cases (N) }\end{array}$ & $R^{a}$ & $95 \% \mathrm{Cl}$ \\
\hline All lung cancers & 27192 & 1.00 & .. & 2591 & 1.09 & $1.05-1.14$ & 287 & 1.16 & $1.03-1.31$ & 67 & 1.15 & $0.90-1.46$ \\
\hline Squamous-cell carcinoma & 9275 & 1.00 & .. & 870 & 1.07 & $0.99-1.15$ & 110 & 1.26 & $1.04-1.53$ & 29 & 1.55 & $1.08-2.24$ \\
\hline Small-cell carcinoma & 4570 & 1.00 &.. & 479 & 1.15 & $1.04-1.27$ & 46 & 1.10 & $0.82-1.48$ & 7 & 0.83 & $0.40-1.75$ \\
\hline Adenocarcinoma & 3379 & 1.00 & .. & 342 & 1.08 & $0.95-1.21$ & 46 & 1.42 & $1.06-1.91$ & 7 & 1.14 & $0.54-2.40$ \\
\hline
\end{tabular}

a Adjusted for smoking, exposure to asbestos and silica, socioeconomic status, age, and periods of follow-up, the reference category being unexposed workers.

benzo(a)pyrene (in the FINJEM, benzo(a)pyrene is an indicator for polyclic aromatic hydrocarbons), plumbers and some subgroups of welders to asbestos, silica and benzo(a)pyrene, and sheet metal workers to nickel and chromium. We minimized the effect of confounding by adding exposure to asbestos, silica, and smoking to the models and excluding worker groups with high exposure to confounders from the study population.

The strengths of our study were the large population-based cohort, a sufficient latency period, the high-coverage data on incident cancer cases from the Finnish Cancer Register, and the availability of exposure estimates for major confounders. The identification of the cohort and the follow-up for incident cancer cases, emigration, and vital status are virtually complete (17). Stability is relatively high in most occupations (31), and therefore the cross-sectional information on occupation corresponds rather well to life-long occupational history. This correspondence is especially true for the older populations in Finland, whose turnover rate between occupations is low.

Social class was a satisfactory approximation for a whole range of lifestyle-related factors in the present study. The adjustment for social class often gives the same results as the use of carefully collected data on specific lifestyle factors (32). Therefore we adjusted the relative risks for socioeconomic status.

Although, nowadays in Finland, smoking coincides with poor socioeconomic status, in our modeling, smoking had an effect on lung cancer that was partially independent of social class and was therefore included in the final model. Our smoking data (1978-1991) are partially too recent in terms of the causation of the cancers diagnosed in 1971-1995. An adjustment based on these smoking data might have biased the relative risk estimates if the recent occupation-specific smoking habits did not correlate with those in earlier decades. Fortunately the time trends for smoking among Finnish men have shown a rather parallel decrease in most population subgroups, and therefore it is justified to use the smoking estimates from 1978-1991 to represent the long-time relative differences in smoking prevalence (16). Still, as in any study related to the etiology of lung cancer, residual confounding may have had an effect on the relative risk estimates.

The current FINJEM-based method has been adopted for the analysis of registered-based data sets in studies in 
European countries, and this study method replicates a risk ratio similar to that found in previous studies (16). The ecological fallacy that theoretically might dilute or artificially create associations in a study based on aggregated data like the current one has been a problem in earlier studies in which it has been possible to compare relative risks derived from individual-level data and group-level data (32).

In conclusion, our study suggests that iron fumes or dust and welding fumes may have caused an elevated risk of lung cancer among Finnish male workers. Simultaneous exposure to other potential lung carcinogens in the workplace may have affected these results. The clustering of the excess risk especially with regard to squamous-cell cancer is a new finding and requires further investigation. The possible synergic and antagonistic effects of the mixed exposures are a challenge for future studies on exposure to iron fumes or dust and welding fumes.

\section{References}

1. Kauppinen T, Toikkanen J, Pukkala E. From cross-tabulations to multipurpose exposure information systems: a new job-exposure matrix. Am J Ind Med. 1998;33(4):409-17.

2. Centers for Disease Control and Prevention (CDC). Publication of NIOSH criteria documents on welding, and brazing, thermal cutting and on radon progeny. MMWR Morb Mortal Wkly Rep. 1988;37(35):545-7.

3. Sørensen AR, Thulstrup AM, Hansen J, Ramlau-Hansen CH, Meersohn A, Skytthe A, et al. Risk of lung cancer according to mild steel and stainless steel welding. Scand J Work Environ Health. 2007;33(5):379-86.

4. Ambroise D, Wild P, Moulin JJ. Update of a meta-analysis on lung cancer and welding. Scand J Work Environ Health. 2006;32(1):22-31.

5. Moulin JJ. A meta-analysis of epidemiologic studies of lung cancer in welders. Scand J Work Environ Health. 1997;23(2):104-13.

6. Sjögren B, Hansen KS, Kjuus H, Persson PG. Exposure to stainless steel welding fumes and lung cancer: a meta-analysis. Occup Environ Med. 1994;51(5):335-6.

7. Steenland K, Beaumont J, Elliot L. Lung cancer in mild steel welders. Am J Epidemiol. 1991;133(3):220-9.

8. Antonini JM, Taylor MD, Zimmer AT, Roberts JR. Pulmonary responses to welding fumes: role of metal constituents. J Toxicol Environ Health A. 2004;67(3):233-49.

9. Steenland K, Beaumont J, Hornung R. The use of regression analyses in a cohort mortality study of welders. J Chronic Dis. 1986;39(4):287-94.

10. Stokinger HE. A review of world literature finds iron oxides noncarcinogenic. Am Ind Hyg Assoc J. 1984;45(2):127-33.

11. Andjelkovich DA, Janszen DB, Brown MH, Richardson RB, Miller FJ. Mortality of iron foundry workers, IV: analysis of a subcohort exposed to formaldehyde. J Occup Environ Med. 1995;37(7):826-37.

12. Grimsrud TK, Langseth H, Engeland A, Andersen A. Lung and bladder cancer in a Norwegian municipality with iron and steel producing industry: population based case-control studies. Oc- cup Environ Med. 1998;55(6):387-92.

13. Moulin JJ, Clavel T, Roy D, Dananche B, Marquis N, Fevotte $\mathrm{J}$, et al. Risk of lung cancer in workers producing stainless steel and metallic alloys. Int Arch Occup Environ Health. 2000;73(3):171-80.

14. Billings CG, Howard P. Occupational siderosis and welders' lung: a review. Monaldi Arch Chest Dis. 1993;48(4):304-14.

15. Central Statistical Office of Finland. Population Census 1970: occupation and social position. Helsinki: Central Statistical Office of Finland; 1974.

16. Pukkala E, Guo J, Kyyrönen P, Lindbohm M, Sallmén M, Kauppinen T. National job-exposure matrix in analyses of census-based estimates of occupational cancer risk. Scand J Work Environ Health. 2005;31(2):97-107.

17. Teppo L, Pukkala E, Lehtonen M. Data quality and quality control of a population-based cancer registry: experience in Finland. Acta Oncol. 1994;33(4):365-9.

18. Berg M-A, Peltoniemi J, Puska P. Health behaviour among the Finnish adult population. Helsinki: Finnish National Public Health Institute; 1992. 130 p.

19. Hoshuyama T, Pan G, Tanaka C, Feng Y, Yu L, Liu T, et al. Mortality of iron-steel workers in Anshan, China: a retrospective cohort study. Int J Occup Environ Health. 2006;12(3):193-202.

20. Ahn YS, Park RM, Stayner L, Kang SK, Jang JK. Cancer morbidity in iron and steel workers in Korea. Am J Ind Med. 2006;49(8):647-57.

21. Tola S, Koskela RS, Hernberg S, Järvinen E. Lung cancer mortality among iron foundry workers. J Occup Med. 1979;21(11):753-9.

22. Liss GM. Health effects of welding and cutting fume-an update. Toronto (Canada): Ontario Ministry of Labour; 1996.

23. Antonini JM. Health effects of welding. Crit Rev Toxicol. 2003;33(1):61-103.

24. Buerke U, Schneider J, Rosler J, Woitowitz HJ. Interstitial pulmonary fibrosis after severe exposure to welding fumes. Am J Ind Med. 2002;41(4):259-68.

25. Samet JM. Does idiopathic pulmonary fibrosis increase lung cancer risk? Am J Respir Crit Care Med. 2000;161:1-2.

26. Lasfargues G, Phan Van J, Lavandier M, Renault B, Renjard $\mathrm{L}$, Moline J, et al. Siderose pulmonaire et risques respiratoires a long terme du soudage a l'arc [Pulmonary siderosis and long-term respiratory risks of arc welders]. Rev Mal Respir. 1991;8(3):304-6.

27. International Agency for Research on Cancer (IARC). Chromium, nickel, and welding. Lyon (France): IARC; 1990. 447 p. IARC Monographs on the evaluation of carcinogenic risks to Humans, vol 49.

28. Sjögren B, Langård S. Re: Pulmonary effects of welding fumes: review of worker and experimental animal studies. Am J Ind Med. 2004;45(5):478-9.

29. Mohr U, Ernst H, Roller M, Pott F. Pulmonary tumor types induced in Wistar rats of the so-called "19-dust study". Exp Toxicol Pathol. 2006;58(1):13-20.

30. International Agency for Research on Cancer (IARC). Mechanisms of fibre carcinogenesis. Lyon (France): IARC; 1996. IARC Scientific Publications, no 140.

31. Kolari R. Occupational mobility in Finland 1975/1980/1985. Helsinki: Central Statistical Office of Finland; 1989. Studies, no 160.

32. Pukkala E. Cancer risk by social class and occupation: a survey of 109,000 cancer cases among Finns of working age. Basel: Kanger. Contributions to epidemiologi and biotatistics, vol 7. 1995.

Received for publication: 26 June 2008 